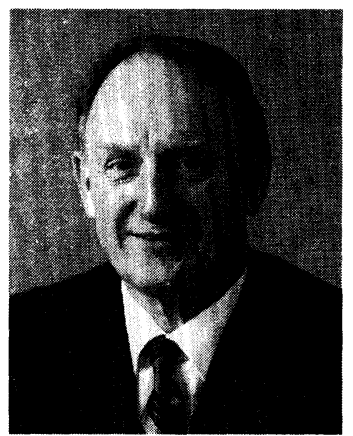

\section{Manuscripts Often Have to Be Revised}

My relatively short experience as an editor of a journal has already taught me a great deal about authors and reviewers. That is, I have relearned a great deal about human nature, and you might be surprised to read that much of it is very positive. Most reviewers take their role seriously, going through the paper with great care, trying to take the author's point of view and seeing how the manuscript can be improved. Their criticism is generally constructive even when they are pointing out serious errors or shortcomings in the manuscript. The author's reaction to these reviewers' comments is, more often than not, positive and, on many occasions, the author will genuinely thank the reviewers for their diligence and for helping to improve the manuscript. I am sure that authors often feel angry or hurt initially by the reviewers' comments, but then realize that it is a confidential process and that the reviewers are authors themselves.

The result of the review process very often means that a manuscript has to be revised. These revisions can range from a minor change to a major task. In some cases, the manuscript really has to be rewritten. One of the roles of the editor is to make judgments about the revisions and whether they meet the reviewers' comments. There are times when the revised paper needs to go back to the reviewer for a final opinion. For major revisions and rewrites, a rereview of the paper may be required either by the original reviewers or by a new independent reviewer. In the final analysis, the editor has to make the decision and live with the consequences of that decision, whether it is positive or negative. Either way, sometimes the editor satisfies neither the author nor the reviewers!

Inevitably, the process of revision delays the publication process, but it is in the author's best interest to get the paper back to the editor as soon as possible. So what is my experience since December 1, 1990? I would have to say, quite positive. The average time is 6.5 weeks from the date I send the manuscript back to the author with the reviewers' comments to the date that I receive the revised manuscript. The median time is 6 weeks, and the range is from 1 week to 19 weeks. However, I do have two manuscripts that have not yet been returned after 30 weeks. (This information is as of the date of this writing-September 11, 1991.) All of the other manuscripts still out for revision have the chance of falling within the distribution discussed above.

All this raises at least one interesting question. For how long is the review valid? There comes a point in time when the editor has to advise the author that the revised manuscript is still welcome, even expected, but given the time interval, it will have to be considered as a new submission and sent out for review again. Another pleasant task for the editor!

The reader will notice that I have used the term reviewer throughout rather than referee. A matter of taste perhaps. The dictionary informs me that the use of the word referee is certainly appropriate since it means "a person who reviews an esp. technical paper before publication" (Webster's New Collegiate Dictionary); so reviewer seems at least equally appropriate.

We owe a sincere thanks to our reviewers for their work on the journal. Happily, none of them follows $\mathrm{H}$. Pearson's point of view in The Smith of Smiths, published in 1934, in which he writes "I never read a book before reviewing it; it prejudices a man so."

Brian J. Thompson Editor 
January 1992

Smart Materials and Structures

Richard O. Claus

Virginia Polytechnic Institute and State University

Dept. of Electrical Engineering

Fiber and Electro-Optics Research Center

648 Whittemore Hall

Blacksburg, VA 24061

703/231-7203

March 1992

Optics in Poland

Romuald Jozwicki

Warsaw Institute of Technology

Institute of Design of Precision and Optical Instruments

ul. Chodkiewicza 8

02-525 Warsaw, Poland

April 1992

Optical Methods and Means of

Information Processing

Mikhail M. Miroshnikov

S.I. Vavilov State Optical Institute

199034, Birjevaya Liniya 12

Leningrad, USSR

May 1992

Optical Implementation of Information

Processing, Pattern Recognition, and

Neural Networks

Bahram Javidi

University of Connecticut

Department of Electrical and Systems Engineering

Room 312, U-157

260 Glenbrook Road

Storrs, CT 06269-3157

203/486-2867

203/486-0318 FAX

June 1992

Adaptive Signal Processing

Simon Haykin

McMaster University

Communications Research Laboratory

1280 Main Street West

Hamilton, Ontario L8S 4K1 Canada

416/525-9140

July 1992

Biomedical Optics

Abraham Katzir

Tel Aviv University

School of Physics

69978 Tel Aviv, Israel

011-972-3-421648

011-972-3-415850 FAX

Manuscripts due Dec. 15, 1991.

August 1992

Optical Engineering and U.K. Industry

Lionel R. Baker

Sira Ltd.

South Hill, Chislehurst

Kent BR7 5EH, United Kingdom

+44814672636

+44 814676515 FAX

R. J. Parker

Rolls Royce plc

P.O. Box 31

Derby DE2 8BJ, United Kingdom

Manuscripts due Jan. 1, 1992.
September 1992

Wavelet Transform

Harold H. Szu

U.S. Navy

Naval Surface Warfare Center, Code R44

10901 New Hampshire Ave.

Silver Spring, MD 20903-5000

301/394-3097

301/394-3923 FAX

Manuscripts due March 23, 1992.

\section{October 1992}

\section{Acousto-Optics}

Ting-Chung Poon

Virginia Polytechnic Institute and State University

Bradley Department of Electrical Engineering

Optical Image Processing Laboratory

Blacksburg, VA 24061

703/231-4876

703/231-3362 FAX

This special issue will focus on all aspects of research on acousto-optic effects and devices as well as their signal and image processing applications. Manuscripts due Feb. 1, 1992.

\section{November 1992}

Relay Mirror Experiment

Paul W. Kervin

USAF Phillips Laboratory

PL/LMA (OL-YY)

P. O. Box 758

Puunene, HI 96784

808/871-7160

808/877-1231 FAX

This special issue will cover the Relay Mirror Experiment and associated experiments. Topics will include the development, deployment, operation, and performance of the space-based Relay Mirror and its associated ground-based equipment. Manuscripts due April 1, 1992.

\section{December 1992}

Automatic Target Recognition

Firooz Sadjadi

Systems and Research Center

Honeywell Inc.

3660 Technology Drive

Minneapolis, MN 55418

612/782-7543

\section{2/782-7438 FAX}

The areas to be considered for inclusion are sonar, radar, laser and passive IR, visible ATR techniques, modeling of sensors, target segmentation, detection and tracking, model-based target recognition, multisensor processing and sensor fusion for ATR, role of performance evaluation in ATR, invariant object recognition, neural networks for ATR, adaptive and learning systems for ATR, and optical processing for ATR. Manuscripts due April 1, 1992.

January 1993

Optical Research in Asia

Chung J. Kuo

National Chung Cheng University

Department of Electrical Engineering

Chiayi, Taiwan 62107

886-5-272-0411, ext. 6210

886-5-272-0862 FAX

unit151@twnmoe10.bitnet E-MAII
Toshimitsu Asakura

Hokkaido University

Research Institute of Applied Electricity

Sapporo, 060 Japan

81-11-716-2111

81-11-758-3173 FAX

asakura@hikari.hokudai. ac.jp E-MAII

Yong $\mathrm{H}$. Lee

Korea Advanced Institute of Science

and Technology

Department of Physics

Yusung-Ku, Taejon, Korea

82-42-829-2536

82-42-861-1458 FAX

This special issue will present innovative re search and development results from Asian coun tries. Every field of photonics will be considered. Prospective authors are invited to submit manuscripts for consideration. Manuscripts due Feb. 1, 1992.

\section{March 1993}

Optical Fiber Reliability II

Hakan H. Yuce

Bellcore

445 South Street

Morristown, NJ 07962

201/829-4945

201/267-9753 FAX

Charles R. Kurkjian

AT\&T Bell Laboratories

600 Mountain Avenue

Murray Hill, NJ 07960-1910

908/582-2378

908/582-2783 FAX

Manuscripts due July 15, 1992.

May 1993

Phase Contrast Microscopy

Maksymilian Pluta

Central Laboratory of Optics ul.

Kamionkowska 18

03805 Warszawa, Poland

48184405 or 48184497

Manuscripts due Oct. 1, 1992.

July 1993

Visual Communication and Image

Processing IV

Kou-Hu Tzou

Bellcore

Room NVC 3B-311

331 Newman Springs Road

Red Bank, NJ 07701-7040

908/758-2857

908/758-0889 FAX

Manuscripts due Dec. 1, 1992.

September 1993

Optical Science and Engineering in Canada

C.P. Grover

National Research Council

Institute for National Measurement Standards

Ottawa, Canada K1A OR6

613/993-2098

613/952-1394 FAX

Manuscripts due Feb. 1, 1993. 